\title{
RENDIMENTO DE ÓLEO ESSENCIAL E CARACTERIZAÇÃO ORGANOLÉPTICA DE FOLHAS DE ASSA-PEIXE SUBMETIDAS A DIFERENTES MÉTODOS DE SECAGEM
}

\author{
The essential oil yield and organoleptic leaves \\ characteristics of "assa-peixe" under various dry methods \\ Ricardo Monteiro Corrêa ${ }^{1}$, Suzan Kelly Vilela Bertolucci ${ }^{2}$, \\ José Eduardo Brasil Pereira Pinto ${ }^{3}$, Érika Soares Reis ${ }^{4}$, Thiago Leal Alves ${ }^{5}$
}

\begin{abstract}
RESUMO
O assa-peixe (Vernonia polyanthes) é muito utilizado na medicina popular em casos de contusões, hemorróidas, infecções do útero e bronquite. Objetivou-se com o presente trabalho avaliar o rendimento de óleo essencial e caracterizar organolepticamente folhas de assa-peixe submetidas a diferentes métodos de secagem. Entre os métodos de secagem avaliados, a secagem natural à sombra, em secador solar e mista (sol e sombra) foram os métodos que apresentaram maiores teores de óleo. $\mathrm{O}$ rendimento de matéria seca de folhas de assa-peixe, após os diferentes métodos de secagem, encontrou-se ao redor de 27,7 a $30,1 \%$. Em todos os métodos de secagem, a cor predominante da face adaxial das folhas de assa-peixe conservou-se verdeescura e da face abaxial verde-clara. No tocante ao odor, observou-se que a secagem à sombra conservou melhor o aroma característico das folhas de $V$. polyanthes.
\end{abstract}

Termos para indexação: Vernonia polyanthes, secagem, óleo essencial, planta medicinal.

\begin{abstract}
"Assa-peixe" (Vernonia polyanthes) is highly used in popular medicine in cases of contusion, hemorrhoid, uterus infections and bronchitis. This present work looked for to evaluate the essential oil yield and to characterize organolepticaly the "assa-peixe" leaves under various dry methods. Among the dry methods evaluated the natural dryness under shade, solar dryer and mixed method (sun and shade) were the ones that showed higher oil contents. The yield of "assa-peixe" dry matter after those different dry methods was around 27.7 and $30.1 \%$. In all dry methods the predominant colour of adaxial face of "assapeixe" leaves remained dark green and abaxial face showed light green. It could also be observed that the dryness under shade kept better the characteristic aroma of $V$. polyanthes leaves.
\end{abstract}

Index terms: Vernonia polyanthes, dry, essential oil, medicinal plant.

(Recebido para publicação em 31 de outubro de 2002 e aprovado em 10 de fevereiro de 2003)

\section{INTRODUÇÃO}

A procura de hábitos mais saudáveis atualmente tem levado as populações à busca de alimentos e medicamentos naturais. Essa tendência promoveu um aumento progressivo na produção e no consumo de medicamentos fitoterápicos e produtos afins, como plantas destinadas a chás, complementos alimentares e "produ-tos naturais", nem sempre produzidos e conservados nas condições apropriadas. Isso tem contribuído, conseqüentemente, para um aumento paralelo de problemas com a qualidade das drogas vegetais.
Desse modo, entre os procedimentos de controle de qualidade pós-colheita de plantas medicinais, a secagem é um processo crucial à preparação adequada das drogas vegetais, que objetiva levar as plantas a baixos teores de umidade. O teor de umidade residual acima de $10 \%$ base úmida nas drogas vegetais favorece o desenvolvimento de fungos e bactérias, bem como possibilita a atividade hidrolítica de diversas enzimas presentes nas células vegetais, levando à degradação dos princípios ativos (SIMÕES, 1999).

Desse modo, porém, o processo de secagem permite a conservação das plantas, mantendo sua qualidade física e química por mais tempo. No caso de

\footnotetext{
1. Engenheiro Agrônomo, Mestrando Fitotecnia, Departamento de Agricultura/DAG, Universidade Federal de Lavras/UFLA - Caixa Postal 37 - $37200-000$ - Lavras, MG. ricardomcesr@ig.com.br

2. Farmacêutica, Ms, DAG/UFLA. suzan@ufla.br

3. Engenheiro Agrônomo, PhD, DAG/UFLA.

4. Bolsista de iniciação científica, DAG/UFLA

5. Engenheiro Agrônomo, Universidade Federal de Viçosa/UFV - 36571-000 - Viçosa, MG.
} 
plantas produtoras de óleo essencial, a secagem deve ser criteriosa em razão da volatilidade dos óleos essenciais. Por isso, a definição de metodologias de secagem mais apropriadas para cada espécie é necessária, visando a assegurar os teores de substâncias ativas.

Blanco (2000a), avaliando a influência de três temperaturas de secagem em estufa com circulação forçada de ar na produção do óleo essencial de menta, verificaram que nas secagens de 60 e $80^{\circ} \mathrm{C}$ não houve diferenças significativas no teor e composição do óleo; porém, o teor obtido em ambas foi $80 \%$ inferior ao obtido na secagem a $40^{\circ} \mathrm{C}$.

A secagem ao sol, em muitas plantas medicinais, é totalmente desaconselhada, pois o processo de fotodecomposição ocorre intensamente, degradando os componentes químicos e ocasionando alterações de cor, sabor e odor na erva (MARTINS et al., 1998).

Em citronela (Cymbopogon winterianus Jowitt. - Poaceae), Rocha et al. (2000) observaram que folhas submetidas à temperatura de secagem de $60^{\circ}$ em estufa com circulação forçada de ar apresentaram o melhor desempenho durante o processo de secagem.

Vernonia polyanthes L. é uma planta da família Asteraceae, produtora de óleo essencial. Conhecida vulgarmente por assa-peixe, suas folhas são empregadas na medicina popular em casos de gripes, resfriados, tosses, bronquite, contusões, hemorróidas e infecções do útero (ANDREÃO, 1999).

Com o presente trabalho teve-se por objetivo avaliar o rendimento de óleo essencial e caracterizar organolepticamente folhas de $V$. polyanthes submetidas a diferentes métodos de secagem.

\section{MATERIAL E MÉTODOS}

O experimento foi conduzido no Laboratório de Cultura de Tecidos Vegetais e Plantas Medicinais do Departamento de Agricultura da Universidade Federal de Lavras (UFLA), no período de 22 de março a 15 de julho de 2002. Exsicatas do material botânico estão depositadas no Herbário ESAL do Departamento de Biologia da UFLA, sob registro $\mathrm{n}^{\mathrm{o}} 13405$.

Folhas de $V$. polyanthes foram colhidas aleatoriamente de exemplares nativos localizados no campus Universitário da UFLA, às 6 horas da manhã, antes da floração. Posteriormente, esse material foi selecionado por catação manual, sendo retirados materiais estranhos e deteriorados. As folhas frescas foram pesadas e divididas eqüitativamente entre quatro tratamentos de secagem: secagem mista (sol e sombra), secagem em estufa, secagem à sombra e em secador solar. A temperatura em cada método de secagem foi medida em termômetro de máxima e mínima.

A secagem mista consistiu em expor as folhas durante a parte da manhã (das 8 até as 12 horas) ao sol e na parte da tarde (das 12 às 17 horas) à sombra. A temperatura média obtida foi de $27^{\circ} \mathrm{C}$.

$\mathrm{Na}$ secagem em estufa, as folhas foram dispostas também uniformemente sobre suas prateleiras metálicas. Para isso, utilizou-se uma estufa de secagem e esterilização com circulação de ar forçada Fanem Mod $320-\mathrm{SE}$, regulada a $35^{\circ} \mathrm{C}$.

Na secagem à sombra, à temperatura ambiente, as folhas foram expostas durante todo o tempo de secagem em local sombreado e ventilado sem a presença de raios solares, cuja temperatura média manteve-se em $25^{\circ} \mathrm{C}$.

Na secagem em secador solar, utilizou-se um secador artesanal, cujo princípio de funcionamento consiste na entrada de ar através de uma abertura na parte inferior e de luz solar através de um vidro transparente localizado na base do secador. $\mathrm{O}$ ar quente formado na base do mesmo é mais leve e sobe por variação na sua massa específica, sendo eliminado por uma chaminé de PVC de $150 \mathrm{~mm}$ de diâmetro e $2,5 \mathrm{~m}$ de altura no topo do equipamento, gerando, com isso, uma circulação de ar quente através do material vegetal. Entre as prateleiras do secador, foi instalado um termômetro de máxima e mínima, por meio do qual se obteve uma temperatura média durante o processo de secagem de $32^{\circ} \mathrm{C}$. Um esquema de sua montagem e funcionamento está representado na Figura 1.

De acordo com dados fornecidos pela Estação Climatológica do Departamento de Engenharia da UFLA, a temperatura média do ar nos dias de secagem variou de 22,9 a $24,5^{\circ} \mathrm{C}$ e a umidade relativa média do ar foi de $64 \%$.

Em todos os tipos de secagem, exceto na estufa a $35^{\circ} \mathrm{C}$, o material coletado foi distribuído sobre bandejas com moldura de madeira e fundo em tela de sombrite, a fim de permitir a circulação do ar.

Após uma perda significativa da umidade, foram retiradas diariamente amostras do material para determinação gravimétrica do teor de umidade, em que foi adotado como critério indicativo do término da secagem a massa constante. Terminada a seca- 
gem, realizou-se uma avaliação subjetiva das folhas, adotando-se como critérios odor e coloração. Essas foram armazenadas em frascos plásticos escuros hermeticamente fechados até a extração do óleo essencial.

Para a extração dos componentes voláteis, foram utilizados $100 \mathrm{~g}$ de folhas secas e trituradas de assa-peixe, as quais foram submetidas à técnica da hidrodestilação em aparelho de Clevenger modificado por 50 minutos. O hidrolato obtido foi particionado com 3 porções de $40 \mathrm{~mL}$ de pentano em funil de separação. Os produtos obtidos da rotaevaporação foram transferidos para frascos de vidro de 30 $\mathrm{mL}$ e levados à estufa a $30^{\circ} \mathrm{C}$, até peso constante, onde a massa dos óleos foi, finalmente, calculada. As frações orgânicas obtidas por particionamento foram reunidas e secas com uma porção de $3 \mathrm{~g}$ de sulfato de magnésio anidro. $\mathrm{O}$ sal foi removido por filtrações simples, e o solvente, evaporado em rotavapor.

As variáveis de resposta do ensaio foram a avaliação organoléptica das folhas, rendimento de matéria seca, tempo gasto na secagem, rendimentos percentuais de óleo. O delineamento experimental foi o totalmente casualizado com três repetições, sendo cada repetição composta de $50 \mathrm{~g}$ de massa seca de folhas, correspondente a cada tipo de secagem. Os dados obtidos foram avaliados de acordo com o teste Tukey ao nível de $5 \%$ de probabilidade de erro.

\section{RESULTADOS E DISCUSSÃO}

\section{Avaliação organoléptica de folhas de assa- peixe}

Entre os testes farmacognósticos, a análise organoléptica é o meio mais simples e rápido de verificar alguns parâmetros de qualidade. Nessa análise, se uma amostra apresentar coloração, consistência, sabor ou odor significativamente diferentes dos estabelecidos, considera-se que ela não preenche os requisitos necessários, sendo rejeitada (SIMÕES, 1999).

Em todos os tratamentos, a cor predominante da face adaxial das folhas de assa-peixe conservou-se verde-escura e a da face abaxial verde-clara. Porém, em relação ao odor, notou-se que a secagem à sombra conservou melhor o cheiro característico das folhas, como se pode observar na Tabela 1.

\section{Rendimento de biomassa seca}

Quando um material vegetal é submetido à secagem, ocorre uma redução considerável da sua massa seca em relação à massa da planta fresca. Em assa-peixe, foi observada uma diferença de $70 \pm 2,3 \%$ entre a massa fresca e seca das folhas. Como se pode observar pela Tabela 1, o rendimento percentual de matéria seca está entre 27,7 e 30,1\%. Essa perda de umidade está dentro da faixa de redução de massa considerada aceitável, de acordo com Sartório (2000), a qual está em torno de 20 a $75 \%$.

\section{Teor de óleo essencial}

Entre os métodos de secagem avaliados, aqueles que apresentaram maiores teores de óleos essenciais foram os que utilizaram a secagem à sombra, mista (sol e sombra) e secador solar, os quais não diferenciaram entre si estatisticamente pelo teste Tukey ao nível de 5\%, conforme se observa na Figura 2.

A secagem em estufa a $35^{\circ} \mathrm{C}$ provocou perdas no teor de óleos essenciais de assa-peixe (Figura 2). Para essa espécie, temperaturas de 25 a $32^{\circ} \mathrm{C}$ não reduziram estatisticamente o rendimento de óleo essencial. Porém, quando utilizou a temperatura de $35^{\circ} \mathrm{C}$ (secagem em estufa), o rendimento de óleo foi significativamente menor.

De acordo com Hertwig (1998), nas plantas produtoras de óleos essenciais, a secagem deve ser bem controlada pelo fato de essas substâncias serem altamente voláteis. Blanco (2000a), utilizando temperaturas de 40,60 e $80^{\circ} \mathrm{C}$ em estufa com circulação de ar, na secagem de mentha (Mentha piperita L. Lamiaceae), observaram que o maior rendimento de óleo essencial foi obtido na temperatura de $40^{\circ} \mathrm{C}$. Blanco (2000b) também estudando a influência da temperatura de secagem no teor de óleo essencial de alecrim (Rosmarinus officinalis L. - Lamiaceae), observaram que quanto maior a temperatura, menor o teor de óleo essencial.

No entanto, Radünz et al. (2002a), avaliando o efeito da temperatura do ar de secagem (ambiente, 40, 50,60 e $70^{\circ} \mathrm{C}$ ) no rendimento extrativo de óleo essencial em alecrim-pimenta (Lippia sidoides Cham. Verbenaceae), utilizando um secador experimental de leito fixo, verificaram que a temperatura de $70^{\circ} \mathrm{C}$ foi o melhor tratamento de secagem. Isso porque apresentou o menor tempo de secagem, sem afetar estatisticamente o rendimento de óleo essencial. 


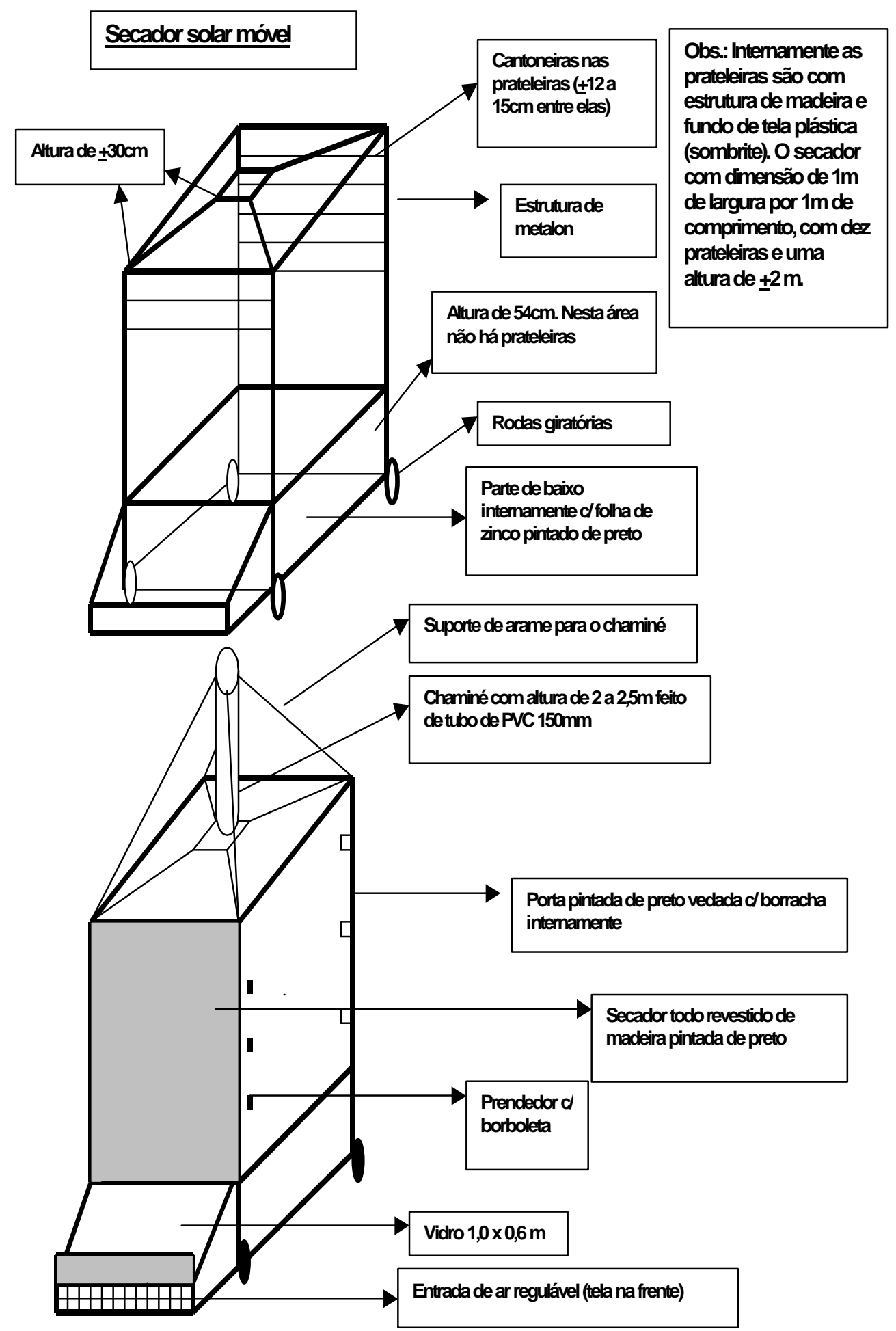

FIGURA 1 - Desenho esquemático do secador solar móvel.

Ciênc. agrotec., Lavras, v. 28, n. 2, p. 339-344, mar./abr., 2004 


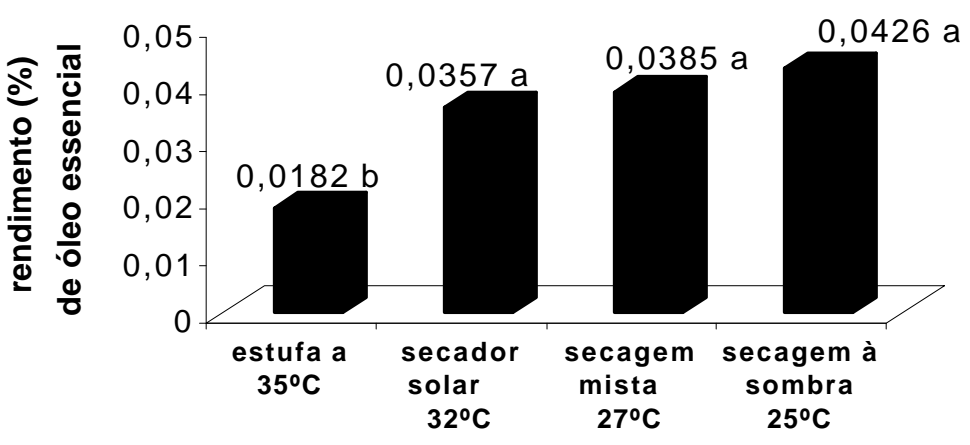

FIGURA 2 - Relação entre os diferentes métodos de secagem de $V$. polyanthes correlacionados com suas temperaturas médias e o rendimento de óleo essencial. Os tratamentos seguidos de mesma letra não diferem entre si pelo teste Tukey ao nível de $5 \%$ de probabilidade.

Por meio desses resultados, verifica-se que a temperatura de secagem deve ser especificamente determinada para cada droga vegetal em particular, uma vez que se constatou que afeta não só a quantidade dos princípios ativos, como também a qualidade desses, como descreveram Radünz et al. (2002b). Esses autores, estudando a influência da temperatura de secagem sobre a composição química do óleo essencial de alecrim-pimenta, observaram que as temperaturas do ar de secagem de $40,50,60$ e $70^{\circ} \mathrm{C}$ não afetaram os rendimentos de $p$-cimeno e timol desse óleo essencial em relação ao material fresco; entretanto, o rendimento extrativo de cariofileno aumentou com o incremento na temperatura do ar de secagem.

O menor rendimento de óleo essencial das folhas de assa-peixe, secas em estufa, também pode ser atribuído ao fato de esse método apresentar circulação de ar forçada, o que pode ter contribuído para a maior volatilização do óleo essencial.

Com relação ao tempo gasto na secagem, a secagem realizada à sombra foi a que mais demorou (54 horas), entre os métodos de secagem avaliados no presente trabalho. Embora a secagem à sombra seja um dos processos mais viáveis para a secagem de plantas medicinais para pequenos produtores, por evitar altos investimentos, bem como sua eficiência ter sido demonstrada por outros autores, como Pi- nheiro (2002), em estudos sobre secagem com Lychnophora pinaster Mart. (Asteraceae), por ser um processo mais lento, pode facilitar a decomposição da droga vegetal em função da presença de enzimas e proliferação microbiana. Radünz et al. (2002a) demonstraram em seus estudos sobre secagem em alecrim-pimenta que a secagem à temperatura ambiente foi um processo muito longo e favoreceu o desenvolvimento de fungos, alteração da coloração do produto final e degradação do óleo essencial.

Nesse caso, a secagem mista e em secador solar podem solucionar esse problema, pois apresentaram tempos de secagem menores, respectivamente 25 e 25,5 h (Tabela 1). No presente trabalho, a secagem mista, além de reduzir o tempo de secagem, não alterou estatisticamente o teor de substâncias voláteis nas folhas de assa-peixe (Figura 2).

$\mathrm{O}$ secador solar mostrou ser um equipamento apropriado para a secagem de folhas de assa-peixe, pois, em comparação aos demais métodos estudados, apresentou as vantagens de efetuar uma secagem rápida, que também não afetou o teor de óleos essenciais e as características organolépticas da droga vegetal. Esse é um secador de fácil e barata construção que pode ser utilizado com praticidade e eficiência por pequenos produtores no processamento pós-colheita de plantas medicinais. 
TABELA 1 - Relação entre os diferentes métodos de secagem e o tempo de secagem gasto, rendimento de percentual de matéria seca (RMS) e análise subjetiva das folhas de $V$. polyanthes.

\begin{tabular}{|c|c|c|c|c|c|c|c|c|}
\hline \multirow[b]{2}{*}{$\begin{array}{l}\text { Métodos de } \\
\text { secagem }\end{array}$} & \multirow[b]{2}{*}{$\begin{array}{l}\text { Tempo gasto } \\
\text { na secagem }\end{array}$} & \multirow{2}{*}{$\begin{array}{c}\text { Temperatura } \\
\text { média de } \\
\text { secagem }\end{array}$} & \multirow{2}{*}{$\begin{array}{c}\text { Massa } \\
\text { fresca } \\
(\mathrm{kg}) \\
\end{array}$} & \multirow{2}{*}{$\begin{array}{c}\text { Massa } \\
\text { seca } \\
(\mathrm{kg}) \\
\end{array}$} & \multirow[b]{2}{*}{$\begin{array}{c}\text { RMS } \\
(\%)\end{array}$} & \multicolumn{3}{|c|}{ Análise organoléptica } \\
\hline & & & & & & $\begin{array}{c}\text { Cor da face } \\
\text { adaxial }\end{array}$ & $\begin{array}{l}\text { Cor da face } \\
\text { abaxial }\end{array}$ & Odor \\
\hline Mista & $\begin{array}{c}\text { 10h de sol e } 15 \mathrm{~h} \mathrm{de} \\
\text { sombra }\end{array}$ & $27,2^{\circ} \mathrm{C}$ & 2,1 & 0,633 & 30,1 & Verde-escura & Verde-clara & Suave \\
\hline Estufa & 46 horas & $35^{\circ} \mathrm{C}$ & 2,1 & 0,6 & 28,6 & Verde-escura & Verde-clara & Suave \\
\hline Secador solar & 25,5 horas & $32,3^{\circ} \mathrm{C}$ & 2,1 & 0,6 & 28,6 & Verde-escura & Verde-clara & Suave \\
\hline Secagem à sombra & 54 horas & $25,1^{\circ} \mathrm{C}$ & 2,1 & 0,581 & 27,7 & Verde-escura & Verde-clara & forte \\
\hline
\end{tabular}

\section{CONCLUSÕES}

Os diferentes métodos de secagem não alteraram a coloração das folhas de assa-peixe. A secagem à sombra conservou melhor o odor característico das folhas, porém, em relação ao teor de óleo essencial, as secagens à sombra, mista e em secador solar proporcionaram maiores teores, em comparação com a secagem em estufa. A secagem em estufa com circulação forçada de ar à temperatura de $35^{\circ} \mathrm{C}$ aumentou a liberação de compostos voláteis, diminuindo, conseqüentemente, o teor de óleo essencial.

O rendimento de matéria seca de folhas de assapeixe, após os diferentes métodos de secagem, encontrou-se ao redor de 27,7 a $30,1 \%$.

\section{AGRADECIMENTO}

Ao CNPq, pelo apoio financeiro.

\section{REFERÊNCIAS BIBLIOGRÁFICAS}

ANDREÃO, A. Estudo do óleo essencial de Vernonia polyanthes. In: ENCONTRO REGIONAL DA SOCIEDADE BRASILEIRA DE QUÍMICA-MG, 8., 1999, Belo Horizonte. Anais... Belo Horizonte: SBQ, 1999. p. 149.

BLANCO. Influência da temperatura de secagem no teor e na composição química do óleo essencial de menta. In: CONGRESSO BRASILEIRO DE OLERICUltURA, 40., 2000, São Pedro. Anais... São Pedro: [s.n.], 2000a. v. 18, p. 901-903.

BLANCO. Influência da temperatura de secagem no teor e na composição química do óleo essencial de alecrim. In: CONGRESSO BRASILEIRO DE OLERICUlTURA, 40., 2000, São Pedro. Anais... São Pedro: [s.n.], 2000b. v. 18, p. 903-905.
HERTWIG, I. F. Plantas aromáticas e medicinais: plantio, colheita, secagem e comercialização. Viçosa: UFV, 1998. 220 p.

MARTINS, E. R.; CASTRO, D. M.; CASTELLANI, D. C.; DIAS, J. E. Plantas medicinais. Viçosa: UFV, 1998. $220 \mathrm{p}$.

PINHEIRO, R. C. Abordagem fitoquímica, rendimento de óleo essencial de Lychonophora pinaster Mart. utilizando dois métodos de secagem. 2002. 41 p. Dissertação (Mestrado em Agroquímica e Agrobioquímica) - Universidade Federal de Lavras, Lavras, 2002.

RADÜNZ, L. L.; MELO, E. C.; MARTINS, P. M. Secagem de alecrim pimenta (Lippia sidoides Cham.) em secador de leito fixo. Revista Brasileira de Plantas Medicinais, Botucatu, v. 5, n. 1, p. 79-82, $2002 \mathrm{a}$.

RADÜNZ, L. L.; MELO, E. C.; BERBERT, P. A. Efeitos da temperatura do ar de secagem sobre a qualidade do óleo essencial de alecrim pimenta (Lippia sidoides Cham.). Revista Brasileira de Armazenamento, Viçosa, v. 27, n. 2, p. 9-13, 2002 b.

ROCHA, S. F. R.; MING, L. C.; MARQUES, M. O. M. Influência de cinco temperaturas de secagem no rendimento e composição do óleo essencial de citronela (Cymbopogon winterianus Jowitt). Revista Brasileira de Plantas Medicinais, Botucatu, v. 3, n. 1, p. 73-78, 2000 .

SARTÓRIO, M. L. Cultivo orgânico de plantas medicinais. Viçosa: Aprenda Fácil, 2000. 258 p.

SIMÕES, D. E. Farmacognosia: da planta ao medicamento. 2. ed. São Paulo: Atheneu, 1999. 540 p. 